\title{
HISTOMETRIC ANALYSIS OF LIGATURE-INDUCED PERIODONTITIS IN RATS: A COMPARISON OF HISTOLOGICAL SECTION PLANES
}

\author{
Tereza Aparecida Delle Vedove SEMENOFF ${ }^{1}$, Alex SEMENOFF-SEGUNDO ${ }^{2}$, Álvaro Francisco BOSCO ${ }^{3}$, \\ Maria José Hitomi NAGATA ${ }^{3}$, Valdir Gouveia GARCIA ${ }^{3}$, Eder Ricardo BIASOLI ${ }^{4}$
}

\author{
1- DDS, MSc, PhD student in Oral Diagnosis, Dental School of Araçatuba, São Paulo State University, Araçatuba, SP, Brazil. \\ 2- DDS, MSc, PhD in Periodontics, Dental School of Araçatuba, São Paulo State University, Araçatuba, SP, Brazil. \\ 3- DDS, MSc, PhD, Assistant Professor, Department of Surgery and Integrated Clinic, Dental School of Araçatuba, São Paulo State University, \\ Araçatuba, SP, Brazil. \\ 4- DDS, MSc, PhD, Assistant Professor of Stomatology, Dental School of Araçatuba, São Paulo State University, Araçatuba, SP, Brazil.
}

Corresponding address: Tereza Aparecida Delle Vedove Semenoff - Rua da Aviação, 1800, Residencial Itamaracá bloco 11, apto 11, Bairro Aviação, 16056-275 Araçatuba, SP, Brasil..E-mail: t.semenoff@uol.com.br

Received: December 19, 2007 - Modification: March 1, 2008 - Accepted: March 31, 2008

\begin{abstract}
$T_{\text {re }}$

he purpose of this study was to analyze the histometry of ligature-induced periodontitis in rats at different histological section depths. Sixteen male adult Wistar rats were randomly assigned to two groups: ligature and control. In the ligature group, rats received a sterile $4 / 0$ silk ligature around the maxillary right 2 nd molar. Thirty serial sections containing the 1 st and 2nd molars, in which the coronal and root pulp, cementoenamel junction (CEJ) in the mesial side of the 2nd molar, interproximal alveolar bone and connective fiber attachment were clearly visible, were selected for histometric analysis. The histological sections were clustered in groups of 10 sections corresponding the buccal (B), central (C) and lingual (L) regions of the of periodontal tissue samples. The distance between the CEJ in the mesial side of the 2nd molar and the attached periodontal ligament fibers (CEJ-PL) as well as the distance between the CEJ and the alveolar bone crest (CEJ-BC) were determined. From CEJ-PL and CEJ-BC distances measured for each specimen, the measurements obtained in the $\mathrm{B}, \mathrm{L}$ and $\mathrm{C}$ regions were recorded individually and together. Data were submitted to statistical analysis. Significant differences $(\mathrm{p}<0.001)$ were observed between the control and ligature groups regarding CEJ-PL $(0.05 \mathrm{~mm}$ and $0.26 \mathrm{~mm}$, respectively $)$ and CEJ-BC $(0.47 \mathrm{~mm}$ and $0.77 \mathrm{~mm}$, respectively) measurements. Regarding the depth of the buccal, central and lingual planes, the means of CEJ-PL and CEJ-BC of both groups showed no statistically significant differences $(p>0.05)$. In conclusion, the selection of 10 serial sections of the central region of periodontal tissue samples at any depth can be considered as representative for the evaluation of periodontal ligament fiber attachment and bone loss in ligature-induced periodontitis in rats.
\end{abstract}

Key Words: Experimental periodontitis, methodology. Periodontal diseases. Rats.

\section{INTRODUCTION}

The induction of periodontal disease by ligature placement is widely used in animal studies ${ }^{6,25,26}$. Although criticism of this experimental model of induced periodontitis exists $^{17}$, it remains a good option to collect information regarding the etiopathogenesis of periodontal disease.

The methodologies used to quantify the progression of ligature-induced periodontitis vary considerably, which means that diverse forms of analysis are equally available $2,5,12,13,16,17,21$

Most studies report that histological sections for qualitative and/or quantitative analyses are obtained from the central portion of the region to be evaluated, being selected 1 to 6 sections on average ${ }^{2,12,18,21,22,23,26,30}$. This means that the examiner has a universe of possibilities to select the most central sections of the tissue samples. Thus, some doubts arise regarding the reliability of the examiner's choice and the representativeness of a histological section for the analysis of the results. In this context, the purpose of this study was to analyze the histometry of ligature-induced periodontitis in rats at different histological section depths.

\section{MATERIALAND METHODS}

\section{Animals}

Sixteen male Wistar rats (Rattus norvegicus) with initial mean weight of 290-315 g were used. The animals were acclimatized to the housing conditions during 2 weeks. Four 
rats were housed in each cage and maintained under 12hour light/dark cycle at a temperature of $23^{\circ} \mathrm{C}$ and relative humidity of $50 \%$ with access to standard rat chow pellets and water ad libitum. The study protocol was independently reviewed and approved by the Ethics in Animal Experimentation Committee of the Dental School of Araçatuba, UNESP, Brazil.

\section{Experimental Induction of Periodontitis}

Eight rats were randomly assigned to the ligature group and 8 to the control group. All procedures of periodontal disease induction were performed under general anesthesia by intramuscular injection of a combination of $0.1 \mathrm{~mL}$ ketamine hydrochloride (50 mg/mL; Dopalen; Agribrands Saúde Animal, Paulínia, SP, Brazil) and $0.05 \mathrm{~mL}$ xylazine hydrochloride (Rompun; Bayer Saúde Animal, São Paulo, SP, Brazil; $2 \mathrm{~g} / 100 \mathrm{~mL}$ ) for each $100 \mathrm{~g}$ body weight. After anesthesia, sterile 4/0 silk ligatures (Ethicon, Johnson e Johnson, São Paulo, SP, Brazil) were placed around the maxillary right 2 nd molars ${ }^{26,27}$. The rats were euthanized by cervical dislocation after 60 days.

\section{Histological Examination}

The right segments of the maxilla was dissected and fixed in $10 \%$ neutral buffered formalin for $48 \mathrm{~h}$, decalcified in $10 \%$ EDTA for approximately 2 weeks, washed, dehydrated in graded alcohol concentrations, cleared in xylol and embedded in paraffin. The paraffin blocks were serially cut in a mesiodistal direction along the long axis of the teeth to provide $7-\mu \mathrm{m}$-thick longitudinal sections. Care was taken to obtain histological sections in which the 1st and 2nd molars, the interproximal alveolar bone crest and the coronal and root pulp chambers were clearly identified. When these criteria were met, serial sectioning was performed until reaching the maximum number of sections possible. Sections representative of each specimen were selected and stained with Harris hematoxylin and eosin. Thirty serial sections containing the 1st and 2nd molars, in which the coronal and root pulp, cementoenamel junction (CEJ) in the mesial side of the 2nd molar, interproximal alveolar bone and connective fiber attachment were clearly visible, were selected for the histometric analysis. The histological sections were clustered in groups of 10 sections corresponding to the buccal (B), central (C) and lingual (L) regions of the periodontal tissue samples.

Images were captured using a trinocular microscope (enamed 2, Carl Zeiss, lens 12.5/0.25, Germany) coupled to a video camera (JVC, Japan). All measurements were carried out in pixels and converted into $\mathrm{mm}$ by a blinded examiner using a digital image-processing software (ImageLab 2000; Diracon Bio Informática Ltda., Vargem Grande do Sul, SP, Brazil). The following histometric parameters were evaluated: (a) distance between the CEJ in the mesial side of the 2nd molar and the attached periodontal ligament fibers (CEJPL), established as histological attachment loss; (b) distance between the CEJ and the alveolar bone crest (CEJ-BC), established as histological bone loss. From CEJ-PL and CEJ$\mathrm{BC}$ distances measured for each specimen, the measurements obtained in the $\mathrm{B}, \mathrm{L}$ and $\mathrm{C}$ regions were recorded individually and together (Figure 1). A single examiner blinded to the treatment groups performed the histometric analysis.

Intraexaminer reproducibility was checked before and during the histometric analysis. Sixty sections were selected at random from the ligature group and analyzed twice with a 1-week interval between measurements. In order to evaluate intraexaminer reproducibility during histometric analysis, the first section of every 15 analyzed sections was reexamined ${ }^{29}$. Paired t-test statistics showed no statistically significant

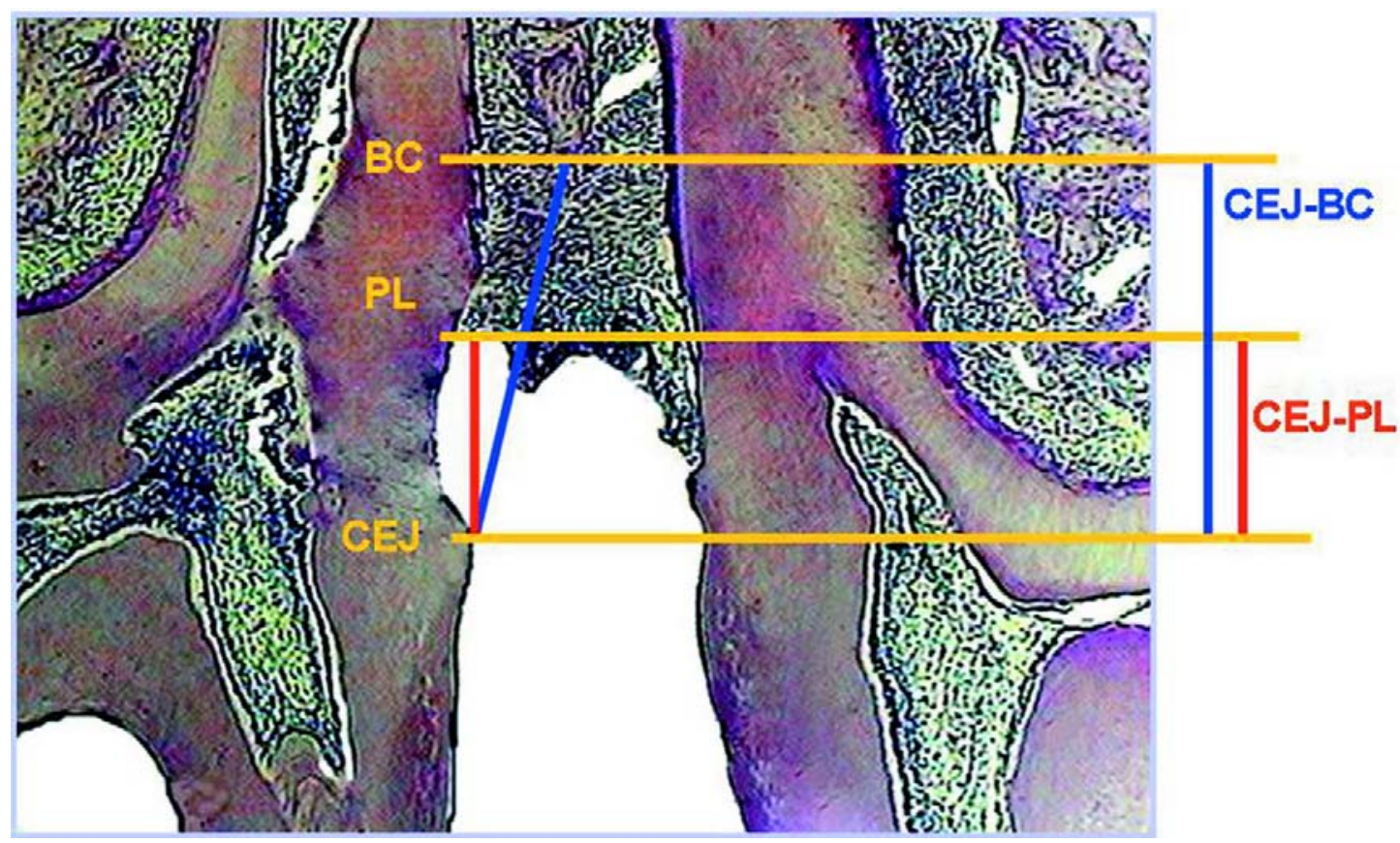

FIGURE 1- Distance between the cementoenamel junction in the mesial side of the 2nd molar and the attached periodontal ligament fibers (CEJ-PL) and distance between the cementoenamel junction and the alveolar bone crest (CEJ-BC) 
differences $(p>0.05)$ in intraexaminer reproducibility for both types of calibration. The standard errors of the mean differences before and during histometric analysis were 0.004 $\mathrm{mm}$ and $0.002 \mathrm{~mm}$ for histological attachment loss, and 0.002 $\mathrm{mm}$ and $0.002 \mathrm{~mm}$ for histological bone loss, respectively.

\section{Statistical analysis}

Data were analyzed statistically by one-way ANOVA with post-hoc Bonferroni correction and at $t$ test for independent samples. A 5\% level of significance was set for all tests.

\section{RESULTS}

One animal from each group (ligature and control) was lost during laboratorial processing.

Comparisons of the CEJ-PL means obtained in the three regions $(\mathrm{B}, \mathrm{C}, \mathrm{L})$ of the control and ligature groups (Table 1$)$ showed no statistically significant differences $(\mathrm{p}>0.05)$ (Figure 2). Comparisons of the CEJ-BC means obtained in the three regions $(\mathrm{B}, \mathrm{C}, \mathrm{L})$ of the control and ligature groups (Table 1) showed no statistically significant differences $(\mathrm{p}>0.05)$. There was statistically significant difference

TABLE 1- Means ( $\pm S D$ ) (in mm) of histometric attachment level (distance between CEJ and PL) and bone level (distance between $C E J$ and $B C$ ) in both groups distributed according to the depth of the histological sections (buccal (B), central (C) and lingual $(L)$ regions, 10 sections per region)

\begin{tabular}{|c|c|c|c|c|}
\hline & \multicolumn{2}{|c|}{ Ligature group } & \multicolumn{2}{|c|}{ Control group } \\
\hline & CEJ-PL & CEJ-BC & CEJ-PL & CEJ-BC \\
\hline B & $0.32 \pm 0.22 \mathrm{a}$ & $0.77 \pm 0.17 \mathrm{a}$ & $0.05 \pm 0.02 \mathrm{a}$ & $0.42 \pm 0.07 a$ \\
\hline C & $0.25 \pm 0.12 a$ & $0.75 \pm 0.15 a$ & $0.04 \pm 0.03 a$ & $0.45 \pm 0.10 a$ \\
\hline $\mathrm{L}$ & $0.22 \pm 0.07 a$ & $0.80 \pm 0.20 a$ & $0.05 \pm 0.05 a$ & $0.50 \pm 0.12 a$ \\
\hline
\end{tabular}

$\mathrm{CEJ}=$ cementoenamel junction; $\mathrm{PL}=$ periodontal ligament; $\mathrm{BC}=$ alveolar bone crest. Different letters in columns indicate statistically significant difference at $5 \%$.

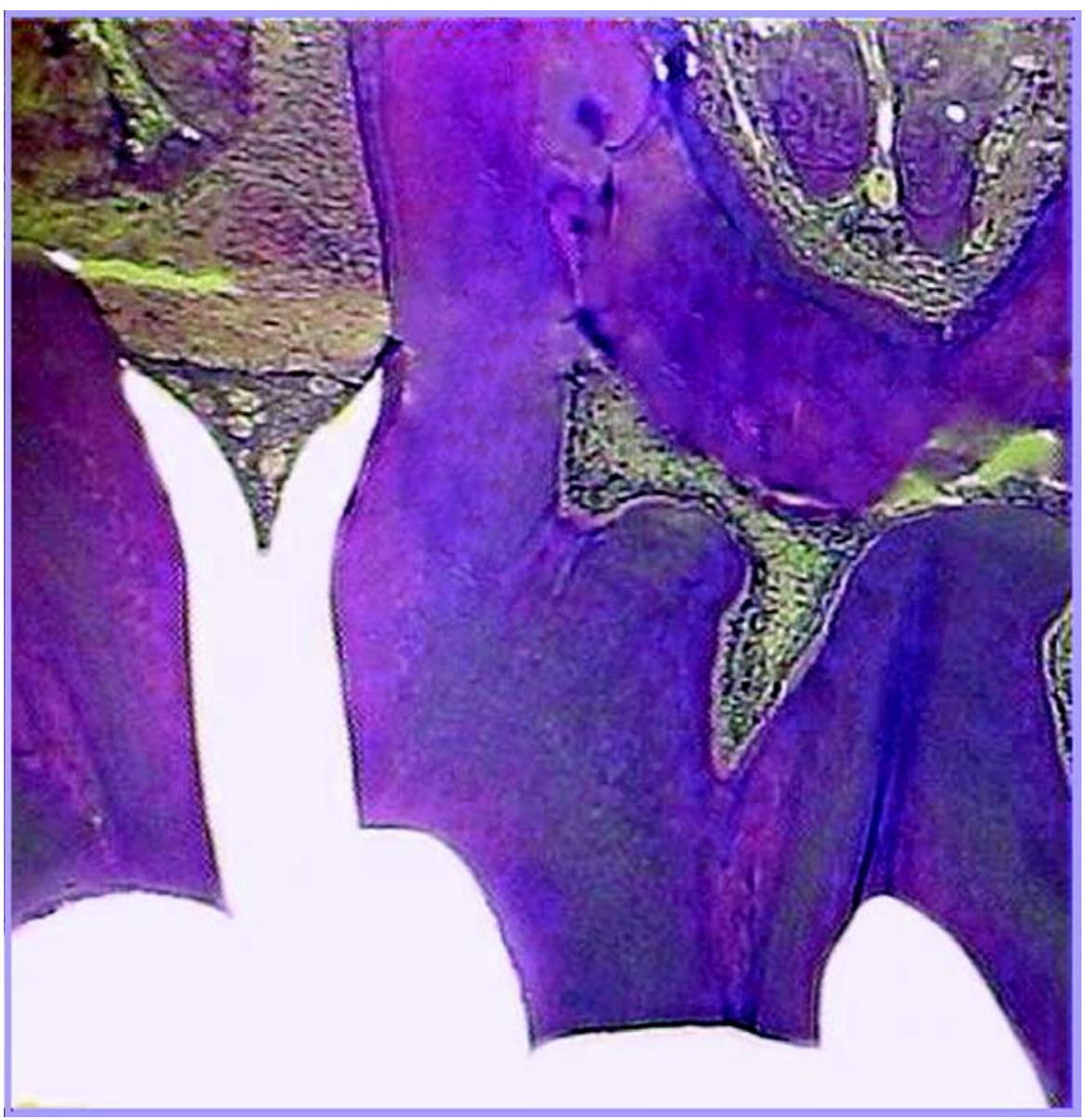

FIGURE 2- Figure illustrating the control group 
between the ligature and control groups regarding histological attachment loss and bone loss $(\mathrm{p}<0.001)$ (Figure 3). and 2 nd molars and one of the respective roots ${ }^{29}$ were clearly identified. A great variability exists regarding the number of sections. In some studies, the number of sections varies

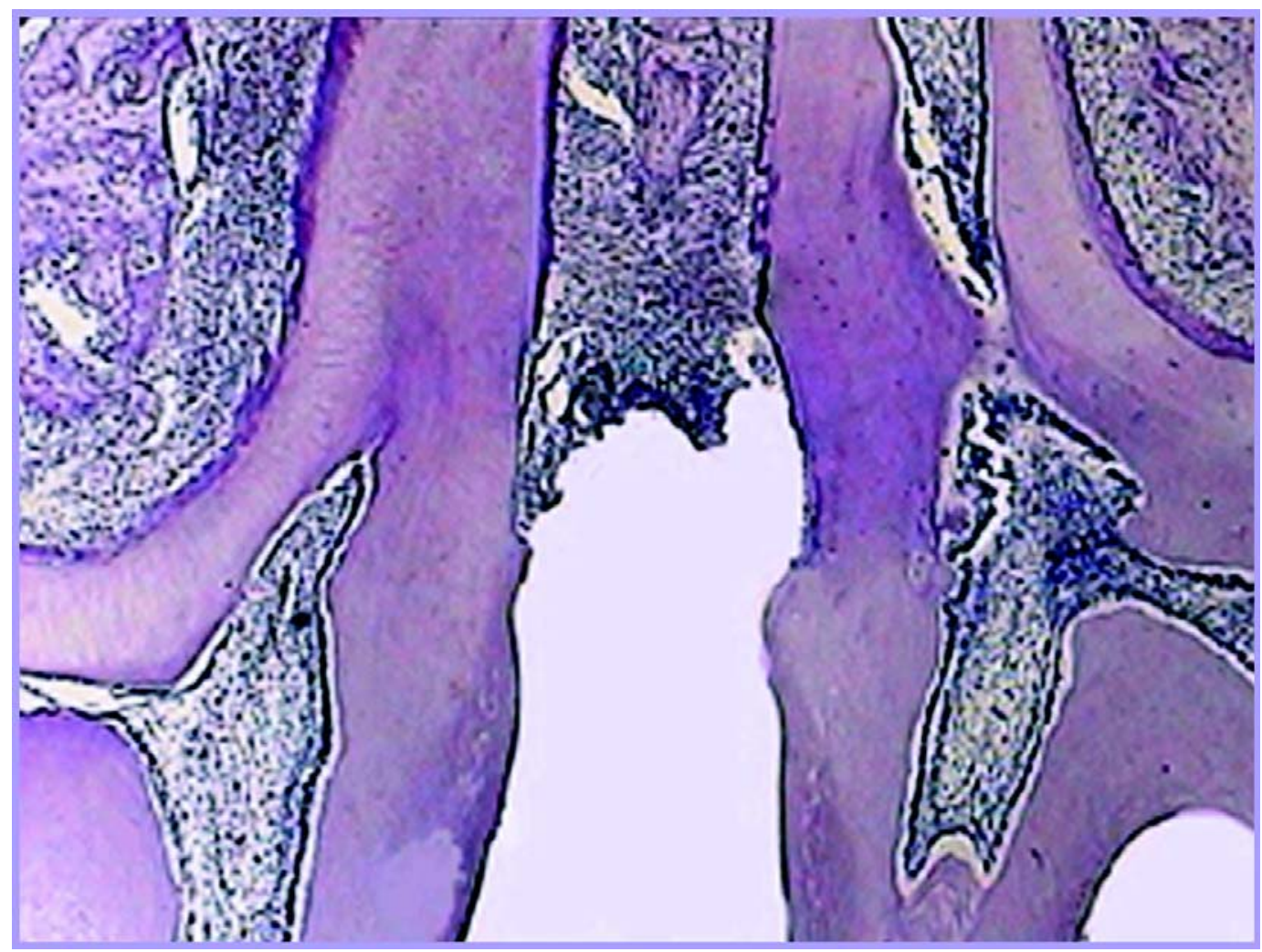

FIGURE 3- Figure illustrating the group with ligature-induced periodontitis

\section{DISCUSSION}

Different methodologies have been proposed for histometric analysis of periodontal tissue loss $2,3,6,9,12,15,19,21,24,27$. Although clinical and radiographic models are a good alternative $e^{7,19}$, the qualitative data from cellular and tissue events ${ }^{8,9,12}$ associated to the quantification of the attachment loss caused by periodontal disease provide more complete information ${ }^{17}$.

However, histological processing and selection of the sections are critical factors in studies based on histometric analysis, which use the central portion of periodontal tissue sections. These steps should be standardized and a sufficient number of samples should be obtained to avoid distortions during comparison of results. In the present study, cutting of sections prior to staining was performed with the aid of a microscope in order to visualize the interproximal space and obtain standardized sections. After HE staining, 30 serial histological sections were obtained from the region comprehended between the buccal and lingual sides, as described in the methodology.

Review of the literature shows that most studies uses histological sections from the central portion of the specimens, without giving any further details regarding how this region is determined. Two studies describe that used histological sections in which the central pulp ${ }^{5}$ and the 1 st from 1 to 6 , while in other studies an unspecified number of sections is merely reported as "the selected histological sections" $2,4,9,10,12,20,21$. In order to make a representative analysis of the process that occurs in the interdental region, Susin and Rösing ${ }^{29}$ (2003), was to obtain semi-serial sections with a 10-step difference between sections, until reaching 60 sections (6 per block). In the present work, 30 serial sections were obtained on the understanding that this was a satisfactory number capable of representing any area from the buccal to the lingual face in the central portion of the periodontal tissue sample.

The choice of CEJ-PL and CEJ-BC as comparative histological parameters was due to the fact that there is a large number of studies using connective attachment loss and bone loss to evaluate periodontal disease, especially for quantification of bone loss $3,21,25,26,29,30$.

In order to have a reliable histometric results, care was taken in the present study with respect to standardization, selection of histological sections and blind examination, as differences in these variables could explain the divergences found in the literature ${ }^{1,14}$. In addition, intraexaminer reproducibility was checked before and during the histometric analysis ${ }^{29}$. No significant differences were found in intraexaminer reproducibility for both types of calibration, as reported elsewhere ${ }^{5,29}$.

The analysis of histological attachment loss and bone 
loss revealed that the different section planes examined in the present study did not differ significantly to each other, with section from the buccal, central and lingual portions of the specimens being representative of disease progression, both in the ligature group and in the control group. The analysis of a group with established ligature-induced periodontists and a periodontally healthy group was important to confirm the readings at several plane depths and in both disease and health conditions.

Despite the loss of two samples (one from each group) during histological processing, sample size was still appropriate and representative for analysis of results $2,26,28,29$.

In the present work, the acquisition of different section planes of the interproximal region, from the region extending from the buccal to the lingual face, made it possible to obtain a good representation of the health to disease process that occurred in this region. This gives rise to some doubts regarding the reliability of the results of several studies due to the great variability existing in the criteria established for determination of the central region of the specimens, and to the different methodologies used for obtaining the histological sections ${ }^{11,23,29,30}$.

\section{CONCLUSION}

In conclusion, the selection of 10 serial sections of the central region of periodontal tissue samples at any depth can be considered as representative for the evaluation of periodontal ligament fiber attachment and bone loss in ligature-induced periodontitis in rats

\section{ACKNOWLEDGMENTS}

To the Mato Grosso State Research Foundation (FAPEMAT, Brazil; Process APQ0036/2005).

\section{REFERENCES}

1- Altman DC. Designing research. In: Altman DC. Practical statistics for medical research. 2nd ed. London: Chapaman \& Hall; 1991. p.74-103.

2- Benatti BB, Nogueira-Filho GR, Diniz MC, Sallum EA, Sallum AW, Nociti FH Jr. Stress may enhance nicotine effects on periodontal tissues: an in vivo study in rats. J Periodontal Res. 2003;38(3):351-

3- Breivik T, Gundersen Y, Osmundsen H, Fonnum F, Opstad PK. Neonatal dexamethasone and chronic tianeptine treatment inhibits ligature-induced periodontitis in adults rats. J Periodontal Res. 2006;41(1):23-32.

4- Breivik T, Stephan M, Brabant GE, Straub RH, Pabst R, Von Hörsten S. Postnatal lipopolysaccharide-induced illness predisposes to periodontal disease in adulthood. Brain Behav Immun. $2002 ; 16(4): 421-38$

5- Breivik T, Thrane PS, Gjermo P, Cools A, Myher T. Effects of hippocampal lesioning on experimental periodontal disease in Wistar rats. J Periodontal Res. 2002;37(5):360-5
6- Breivik T, Thrane PS. Psychoneuroimmune interactions in periodontal disease. In: Alder R, Felten DL, Cohen N. Psychoneuroimmunlogy. 3rd ed. San Diego: Academic Press; 2000. p.627-44.

7- Cavagni J, Soletti AC, Gaio JE, Rösing CK. The effect of dexamethasone in the pathogenesis of ligature-induced periodontal disease in Wistar rats. Braz Oral Res. 2005;19(4):290-4.

8- Di Paola R, Marzocco S, Mazzon E, Dattola F, Rotondo F, Britti $\mathrm{D}$, et al. Effect of Aminoguanidine in ligature-induced periodontitis in rats. J Dent Res. 2004;83(4):343-8.

9- Dumitresco AL, Abd El-Aleen S, Morales-Aza B, Donaldson LF. A model of periodontitis in the rat: effect of lipopolysaccharide on bone resorption, osteoclast activity, and local peptidergic innervation. J Clin Periodontol. 2004;31(8):596-603.

10- Ekuni D, Yamamoto T, Yamanaka R, Tachibana K, Watanabe T. Proteases augment the effects of lipopolysaccharide in rat gingiva. $\mathrm{J}$ Periodontal Res. 2003;38(6):591-6.

11 - Garat JA, Gordillo ME, Ubios AM. Bone response to differente streength orthodontic forces in animals with periodontitis. J Periodontal Res. 2005;40(6):441-5.

12- Gaspersic R, Stiblar-Martincic D, Skaleric U. Influence of restraint stress on ligature-induced periodontitis in rats. Eur J Oral Sci. $2002 ; 110(2): 125-9$

13 - Gyöfi A, Fazekas A, Suba Z, Ender F, Rosivall L. Neurogenic component ligature-induced periodontitis in the rat. J Clin Periodontol. 1994;21(9):601-5.

14- Kingman A, Albandar JM. Methodological aspects of epidemiological studies of periodontal diseases. Periodontol 2000. 2002;29:11-30.

15- Klausen B, Evans RT, Sfintescu C. Two complementary methods of assessing periodontal bone level in rats. Scand J Dent Res. 1989,97(6):494-9.

16- Klausen B, Hougen HP, Fiehn NF. Increased periodontal bone loss in temporarily B Lymphocyte-deficient Rats. J Periodontal Res. $1989 ; 24(6): 384-90$

17- Klausen B. Microbiological and immunological aspects of experimental periodontal disease in rats: a review article. J Periodontol. 1991;62(1):59-73.

18 - Koide M, Suda S, Saitoh S, Ofuji Y, Suzuki T, Yoshie H, et al. In vivo administration of IL-1ß accelerates silk ligature-induced alveolar bone resorption in rats. J Oral Pathol Med. 1995;24(9):420-34.

19- Kuhr A, Papa-Wagner A, Schmoll H, Schwahn C, Kocher T. Observations on experimental marginal periodontitis in rats. J Periodontal Res. 2004;39(2):101-6.

20 - Mandalunis PM, Costa OR, Ubios AM. Dynamics of bone loss in experimental periodontitis. Acta Odontol Scand. 1998;11(1):27-35.

21 - Mitsuda T, Houriuch H, Shinoda H. Effect of topical administration of clodronate on alveolar resorption in rats with experimental periodontitis. J Periodontol. 2002;73(5):479-86.

22 - Nikura K, Takeshita N, Chida N. A novel inhibitor of vacuolar ATPase, FR202126, prevents alveolar bone destruction in experimental periodontitis in rats. J Toxicol Sci. 2005;30(4):297304 . 
23 - Nociti SH Júnior, Nogueira-Filho GR, Tramontina VA, Machado MA, Barros SP, Sallum EA, et al. Histometric evaluation of the effect of nicotine administration on periodontal breakdown: an in vivo study. J Periodontal Res. 2001;36(6):361-6.

24- Ramamurth NS, Xu JW, Bird J, Baxter A, Bhogal R, Wills R, et al. Inhibition of alveolar bone loss by matrix metalloproteinase inhibitors in experimental periodontal disease. J Periodontal Res. 2002;37(1):17 .

25 - Rovin S, Costich ER, Gordon HA. The Influence of bacteria and Irritation in the Initiation of periodontal disease in germfree and conventional rats. J Periodontal Res. 1966;1(3):193-204.

26- Sallay K, Sanavi F, Ring I, Pham P, Berhling UH, Nowotny A. Alveolar bone destruction in the immunosuppressed rat. J Periodontal Res. 1982;17(3):263-74.

27-Sanavi F, Listgarten MA, Boyd F, Sallay K, Nowotny A. The colonization and establishment of invading bacteria in periodontium of ligature-treated immunosuppressed rats. J Periodontol. $1985 ; 56(5): 273-80$.

28- Shapira L, Houri-Haddad Y, Frolov I, Halabi A, Ben-Nathan D The effect of stress on the Inflammatory response to Porphyromonas gingivalis in mouse subcutaneous chamber model. J Periodontol. 1999;70(3):289-93

29- Susin C, Rösing CK. Effect of variable moderate chronic stress on ligature-induced periodontal disease in Wistar Rats. Acta Odontol Scand. 2003;61(5):273-7.

30- Yoshinari N, Kameyama Y, Aoyama Y, Nishiyama H, Nogutchi T. Effect long-term methotrexate-induced neutropenia on experimental periodontal lesion in rats. J Periodontal Res. 1994;29(6):393-400. 